\title{
An Investigation of the Design Potential of Thermochromic Home Textiles Used with Electric Heating Techniques
}

\author{
Hung-Jen Chen ${ }^{1}$ and Lan-Hui Huang ${ }^{2}$ \\ ${ }^{1}$ Department of Fashion Design, Shu-Te University, Kaohsiung 824, Taiwan \\ ${ }^{2}$ Graduate School of Applied Design, Shu-Te University, Kaohsiung 824, Taiwan \\ Correspondence should be addressed to Hung-Jen Chen; hjchen372@gmail.com
}

Received 23 September 2014; Accepted 26 December 2014

Academic Editor: Mo Li

Copyright (C) 2015 H.-J. Chen and L.-H. Huang. This is an open access article distributed under the Creative Commons Attribution License, which permits unrestricted use, distribution, and reproduction in any medium, provided the original work is properly cited.

Thermochromic colorants have been developed since before the 1900s. There are a large number of patents in different applications of thermochromic textiles, but many innovations leave the field of aesthetic and functional textile design unexplored in the area of smart materials. This study aims to develop thermochromic home textiles that change colors and patterns by integrating thermochromic pigments and electric conductive yarns into textile structures. Stainless steel conductive yarns were sewed on textile substrates to enable heat generation to increase fabric temperature. The heat generation and temperature rise could be controlled by monitoring the voltage applied. The experiments of this study focused on analyzing electric resistance and heating properties of the conductive yarns and observing color changing time and color changing effects of the thermochromic textiles. By using the technique in this research, an image of "tai chi" was designed and implemented in a backlighting thermochromic fabric. It illustrates a range of opportunities for thermochromic textiles in new design research directions of Chinese calligraphy and traditional Chinese painting.

\section{Introduction}

Thermochromic materials change color reversibly, especially through the application of thermochromic dyes whose colors change at particular temperatures. Thermochromic materials using microencapsulated dyes were developed in the 1970s and subsequently have been used mainly in the textile and novelty industries [1]. The leuco-dye-type thermochromic system has been most commonly used, which undergoes a reversible change from colored to colorless when subjected to temperature raises [2]. Today, the thermochromic technology has been developed into the smart textiles era and the conjunction of electronic engineering can make an available range of new media for exploitation $[3,4]$.

Thermochromism has been exploited by a few textile designers who have combined aesthetic and functionality in their creative works. Among these designers, Linda has successfully employed thermochromic technology in her research [5], using carbon fibers woven into fabrics, to produce a color and pattern change on the fabric when a power supply is applied. Robertson has presented an illustrated discussion of the potential for creative design applications of thermochromic textiles brought into contact with specifically designed heat-profiling circuitry [6]. The Skin Stories: Charting and Mapping the Skin, which was created by Berzina [7], collects together the results of her multidisciplinary researches. An interesting feature of her work is TouchMe Wallpaper, a temporary handprint that appears on a thermochromic surface triggered by contact with the human hand. Maggie Orth has produced a color changing textile, Electric Plaid, which combines thermochromic printed textiles with electronic circuitry [8]. The conductive yarns are woven into the fabric and activate the thermochromic effect when connected to a power source. Berzowska has developed Shimmering Flower which creates a nonemissive color-change textile display [9]. The thermochromic effect is 


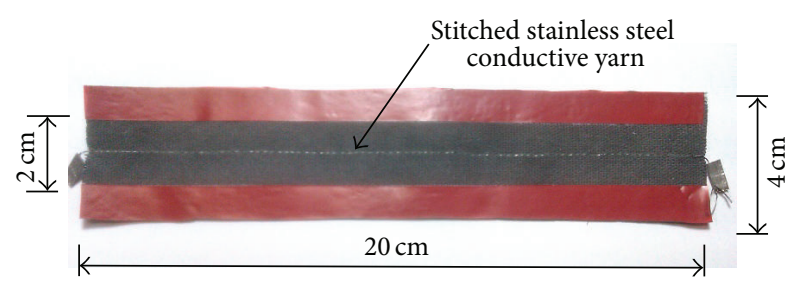

FIGURE 1: The thermochromic printed fabric sample.

activated in areas of individual addressable pixels, the color change being controlled in real time.

This study aims to develop thermochromic home textiles that change colors and patterns by integrating thermochromic pigments and electric conductive yarns into textile structures. The stainless steel conductive yarns were sewed on thermochromic textiles to generate heat for increasing fabric temperature. The heat generation and temperature rise can be controlled by monitoring the voltage applied.

\section{Materials and Methods}

The research focuses on the idea of incorporating a heat generating system into thermochromic printing textiles in order to control the pattern shape and color change on the fabric surface. This functionality is accomplished through the embroidery of a conductive yarn which can convert electric current into resistive heat. Several conductive yarns were considered in this experiment, but only a $100 \%$ stainless steel conductive filament yarn with 100 Tex yarn count was chosen. The yarn contains 90 stainless steel fibers with diameter of $14 \mu \mathrm{m}$ each, and it is twisted in 100 twists per meter. One of its important properties is that it does not fray easily and it is flexible enough to be sewn by a sewing machine. The stainless steel conductive yarn was then stitched in $20 \mathrm{~cm}$ straight line across the middle of a white cotton fabric (plain weave, warp density 50/in, weft density 30/in), which was cut in the size of $4 \mathrm{~cm} \times 20 \mathrm{~cm}$, by using a Brothers sewing machine. Five pieces of these stitched fabrics were then screen-printed with thermochromic reversible leuco dye pigment (30\% binder resin, $70 \%$ thermochromic leuco dye) that is black below $31^{\circ} \mathrm{C}$ and transparent above this temperature. The thermochromic leuco dye pigment was printed in a $2 \mathrm{~cm} \times 20 \mathrm{~cm}$ black rectangular shape which was located in the center of the fabric and covered the stitched stainless steel conductive yarn, and two red tapes covered the rest of the fabric for marking the borderline of the printed area. The thermochromic printed fabric sample is shown in Figure 1.

The stainless steel conductive yarn, at the selvedge of the thermochromic printed fabric sample, was connected to a variable power supply, as shown in Figure 2. The thermocouple of the multidigital meter was placed above the stainless steel conductive yarns to measure the temperature change of the yarn. Different voltages were applied to the samples for observing the thermochromic decolorized effect, and the temperatures which were measured by the multidigital meter were recorded by a computer.

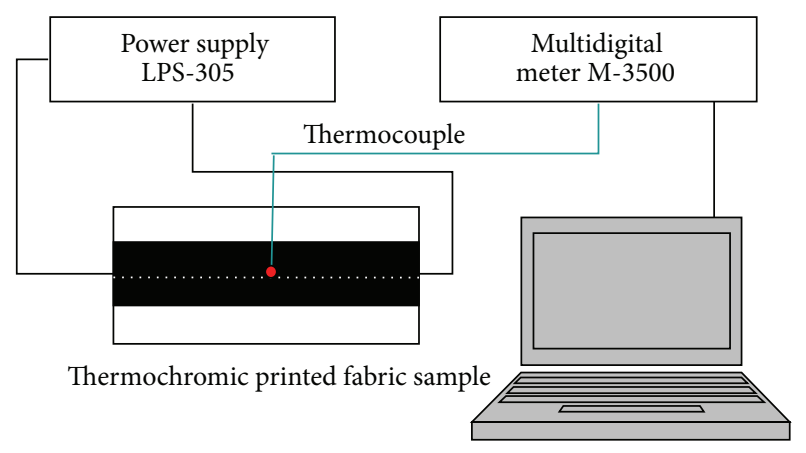

FIgURE 2: The block diagram of experimental configuration.

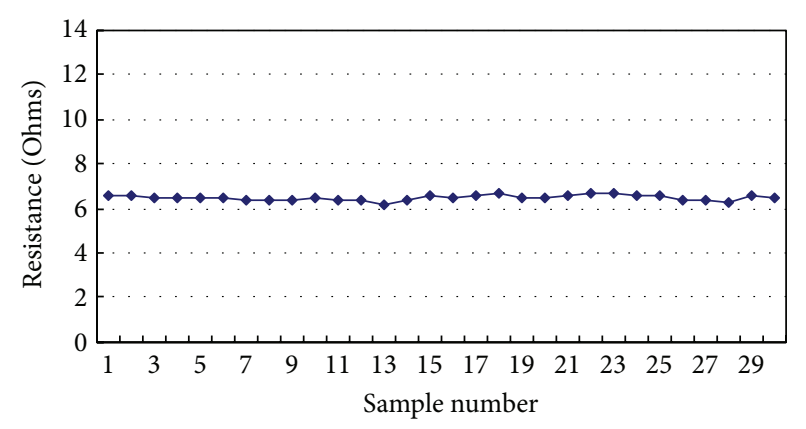

FIgURE 3: The resistance values of $10 \mathrm{~cm}$ stainless steel conductive yarns.

\section{Results and Discussion}

The electric resistance of the stainless steel conductive yarn has to be determined before being used as a heating mechanism to activate thermochromic color-change. Consequently, 30 samples of the stainless steel conductive yarns in $10 \mathrm{~cm}$ length were prepared for the resistance measurements. Figure 3 shows that the stainless steel conductive yarn has an average resistance of $0.65 \Omega / \mathrm{cm}$, and $1.89 \%$ coefficient of variation is obtained. It is clear that the resistance of the stainless steel conductive yarn is quite steady and low, which is very suitable for generating heat in a lower voltage.

The thermochromic printed fabric samples were applied with different voltages, which were $5 \mathrm{~V}, 6 \mathrm{~V}, 7 \mathrm{~V}, 8 \mathrm{~V}$, and $9 \mathrm{~V}$, and the temperatures risen with heating times were recorded and analyzed. Figures 4 and 5 show the relationships between temperature and heating time with $5 \mathrm{~V}$ and $6 \mathrm{~V}$ applied on the samples. They indicate an increase in temperatures as the heating duration increases, but the temperatures of the conductive yarns keep in $70^{\circ} \mathrm{C}-80^{\circ} \mathrm{C}$ after $60 \mathrm{sec}$ heating time. Figures 6,7 , and 8 show the relationships between temperature and heating time with $7 \mathrm{~V}, 8 \mathrm{~V}$, and $9 \mathrm{~V}$ applied on the samples. The temperatures of the figures rise up rapidly and reach $100^{\circ} \mathrm{C}$ within $23 \mathrm{sec}$. Figure 9 shows the linear regression relationship between temperatures $\left(30^{\circ} \mathrm{C}-\right.$ $60^{\circ} \mathrm{C}$ ) and heating times of the samples with different voltages applied $(5 \mathrm{~V}, 6 \mathrm{~V}, 7 \mathrm{~V}, 8 \mathrm{~V}$, and $9 \mathrm{~V})$. It indicates a good linear relationship between temperatures and heating times (coefficient of determination $\left(R^{2}\right)=0.96$ for $5 \mathrm{~V}, 0.99$ for $6 \mathrm{~V}$, 


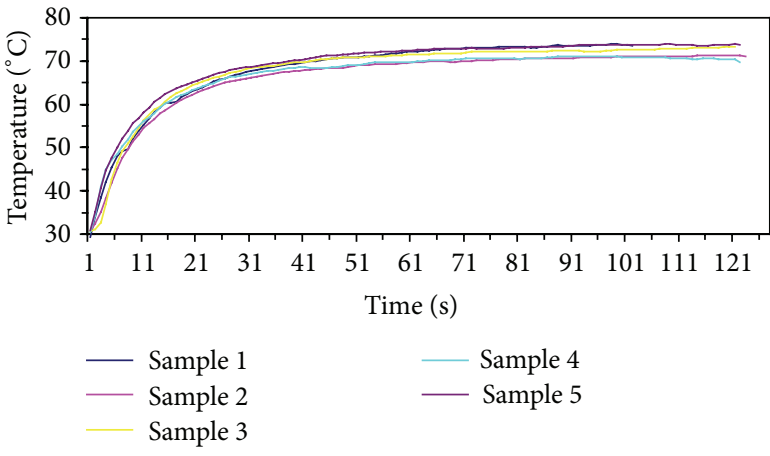

FIGURE 4: The relationship between temperature and heating time of the thermochromic printed fabric samples with 5 voltages applied.

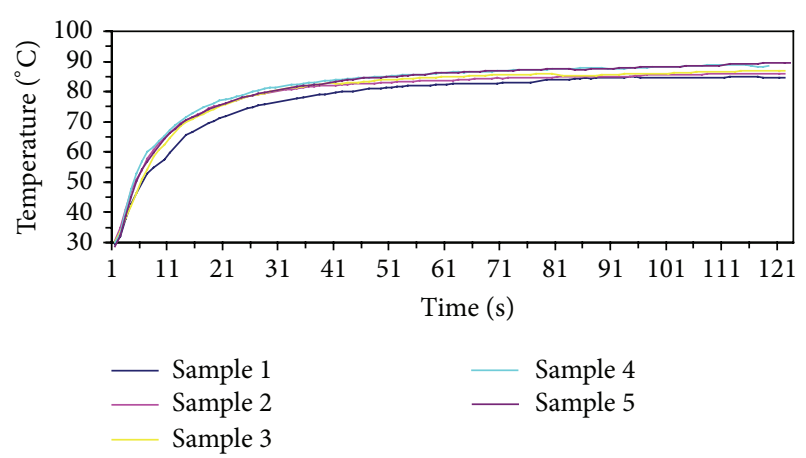

FIGURE 5: The relationship between temperature and heating time of the thermochromic printed fabric samples with 6 voltages applied.

TABLE 1: The temperature rising slopes, the coefficients of determination $\left(R^{2}\right)$, and the electrical powers in Figure 9 with different voltages applied.

\begin{tabular}{lccc}
\hline Voltage $(\mathrm{V})$ & Power $(\mathrm{W})$ & Slope & $\begin{array}{c}\text { Coefficient of } \\
\text { determination }\left(R^{2}\right)\end{array}$ \\
\hline 5 & 1.9 & 1.8 & 0.96 \\
6 & 2.7 & 3.6 & 0.99 \\
7 & 3.7 & 6.2 & 0.99 \\
8 & 4.9 & 11.2 & 0.99 \\
9 & 6.2 & 12.8 & 0.99 \\
\hline
\end{tabular}

0.99 for $7 \mathrm{~V}, 0.99$ for $8 \mathrm{~V}$, and 0.99 for $9 \mathrm{~V}$ ), as shown in Table 1. It also shows that the temperature rising slope increases as voltage is increased.

The decoloration time of the thermochromic printed fabric sample is defined as the period of the black color is totally vanished from the printing area when the stainless steel conductive yarn has been heated by power supply, as shown in Figure 10. The five thermochromic printed fabric samples were tested for the decoloration time with different voltages, namely, $5 \mathrm{~V}, 6 \mathrm{~V}, 7 \mathrm{~V}, 8 \mathrm{~V}$, and $9 \mathrm{~V}$, and the temperatures were also recorded at the decoloration time. The results are summarized in Table 2 . It shows that the higher voltage is applied; the shorter decoloration time of the pattern of the thermochromic printed fabric is needed. This is due

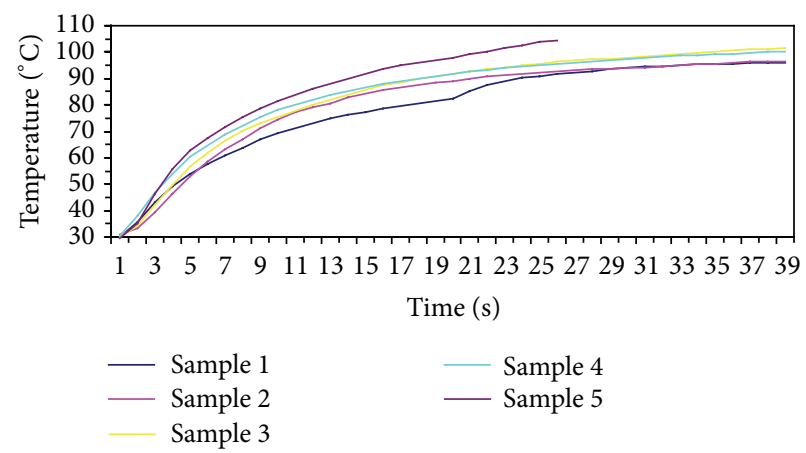

FIGURE 6: The relationship between temperature and heating time of the thermochromic printed fabric samples with 7 voltages applied.

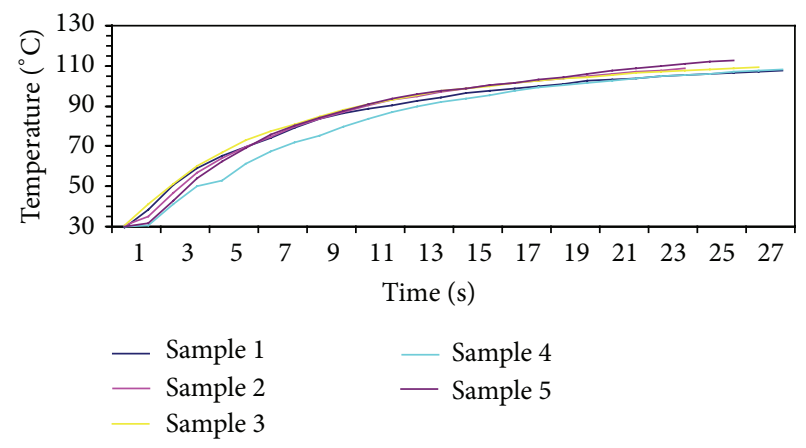

FIGURE 7: The relationship between temperature and heating time of the thermochromic printed fabric samples with 8 voltages applied.

TABLE 2: The thermochromic printed fabric samples, decoloration times, and temperatures with different voltages applied.

\begin{tabular}{lcc}
\hline Voltage $(\mathrm{V})$ & $\begin{array}{c}\text { Decoloration time } \\
(\mathrm{sec})\end{array}$ & $\begin{array}{c}\text { Decoloration } \\
\text { temperature }\left({ }^{\circ} \mathrm{C}\right)\end{array}$ \\
\hline 5 & 42.5 & 65 \\
6 & 29.5 & 75.8 \\
7 & 23 & 86.3 \\
8 & 20 & 100.9 \\
9 & 17.9 & 113.8 \\
\hline
\end{tabular}

to the increasing rate of temperature of the stainless steel conductive yarn which is higher in high voltage to result in the quicker heat diffusion.

Based on the above results, one can control the pattern shape and color change rate on a thermochromic textile by embroidering the stainless steel conductive yarn into a specific pattern and altering the voltage which is applied on it.

During the observation of the decoloration process, it was found that the line-figure activated by the stainless steel conductive yarn has a particularly appealing effect. It reveals a stone rubbing style which fits comfortably into the area of Chinese calligraphy illustration. Inspired by the technique of this study, patterns of four Chinese calligraphies were embroidered on a textile substrate and coated with the black thermochromic leuco dye pigment. Figure 11 shows 


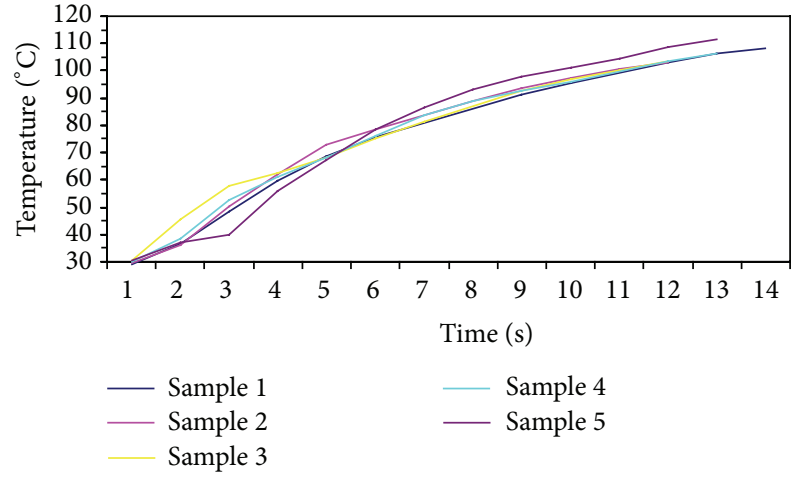

FIGURE 8: The relationship between temperature and heating time of the thermochromic printed fabric samples with 9 voltages applied.

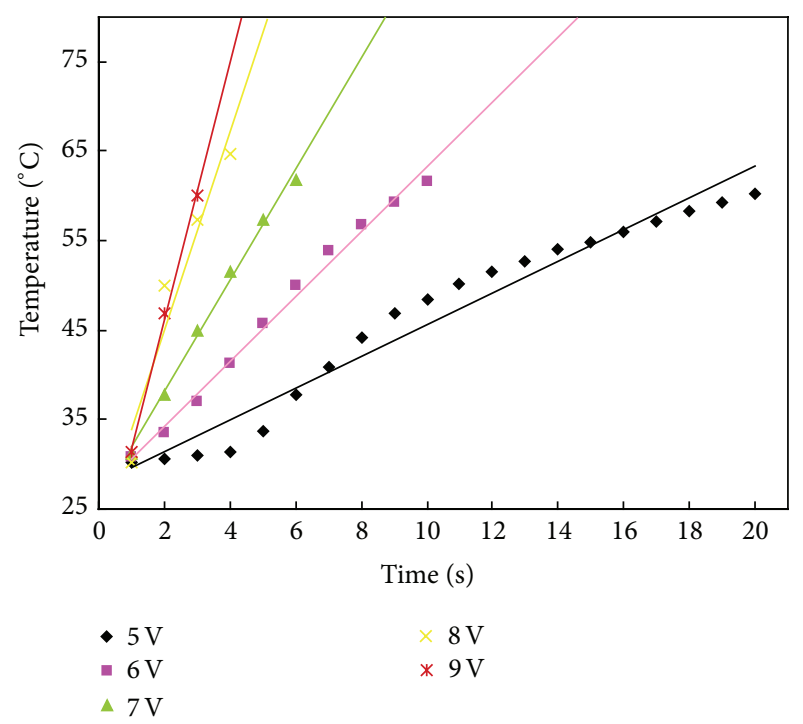

FIGURE 9: The linear regression relationship between temperature $\left(30^{\circ} \mathrm{C}-60^{\circ} \mathrm{C}\right)$ and heating time of the thermochromic printed fabric sample with different voltages applied $(5 \mathrm{~V}, 6 \mathrm{~V}, 7 \mathrm{~V}, 8 \mathrm{~V}$, and $9 \mathrm{~V})$.

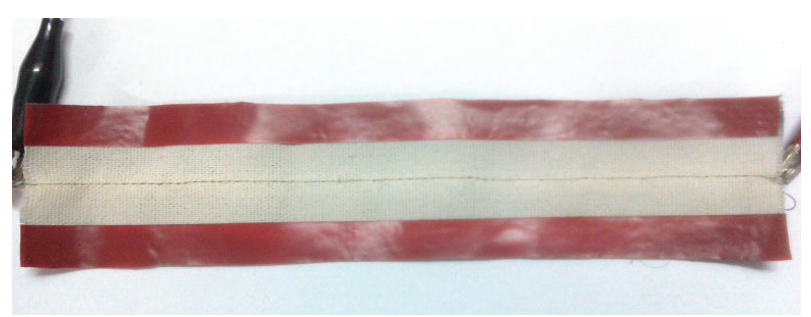

Figure 10: The decoloration effect of the thermochromic printed fabric sample.

the thermochromic effect of four Chinese calligraphies with backlighting when $6 \mathrm{~V}$ was applied on them for $30 \mathrm{sec}$.

Further design was taken for exploiting the graphic capability of the technique. A "tai chi" pattern was created and the sewing paths of the stainless steel conductive yarn were sketched, as shown in Figure 12. The stainless steel conductive yarns in the sewing paths were carefully arranged in $1 \mathrm{~cm}$

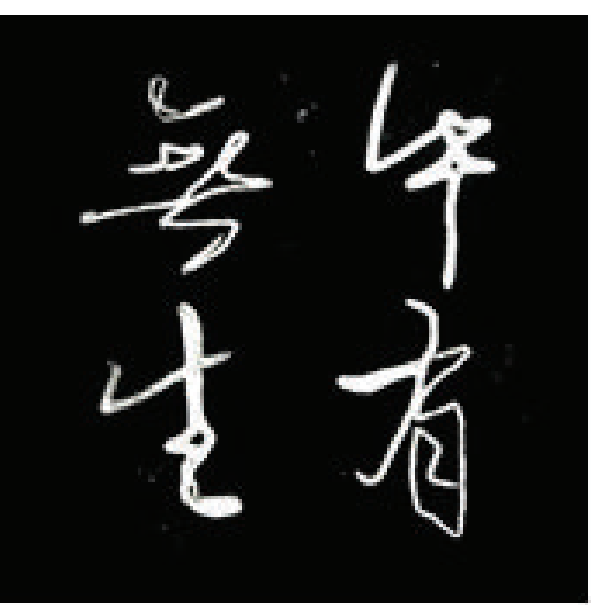

FIGURE 11: The thermochromic effect of Chinese calligraphy with backlighting $(6 \mathrm{~V}, 30 \mathrm{sec})$.

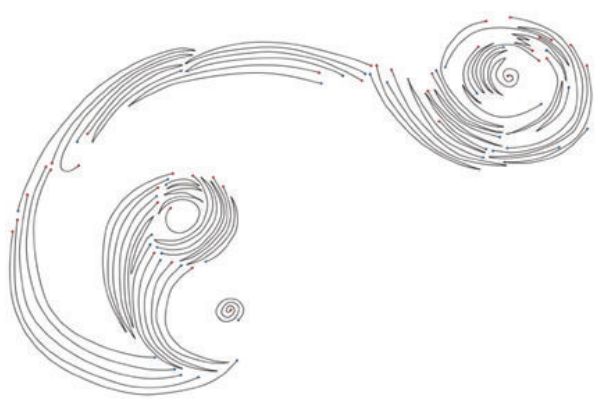

FIGURE 12: The embroidered paths of the stainless steel conductive yarn in the "tai chi" pattern.

apart and $20 \mathrm{~cm}$ in length for the best performance of the thermochromic effect.

The pattern was divided into four electric connecting groups which can be activated successively. There was also provision for switch control on the individual groups. Figure 13 shows the thermochromic effect of the "tai chi" pattern with backlighting when the four pattern groups were switched on and off with $5 \mathrm{~V}$ in a $30 \mathrm{sec}$ sequence. Because of the heat interference between stainless steel conductive yarns, the image of "tai chi" illustrates a "splash-ink" appearance which is similar to the traditional Chinese monochrome painting.

\section{Conclusion}

This study aims to develop thermochromic home textiles which can change colors and patterns by integrating thermochromic pigments and electric conductive yarns into textile structures. The stainless steel conductive yarn, which is used in this research, has an average resistance of $0.65 \Omega / \mathrm{cm}$, and the coefficient of variation of resistance is $1.89 \%$. The stainless steel conductive yarns were stitched on white cotton fabrics. The fabrics were screen-printed with black thermochromic leuco dye pigment. These thermochromic printed fabric samples were applied with different voltages, 


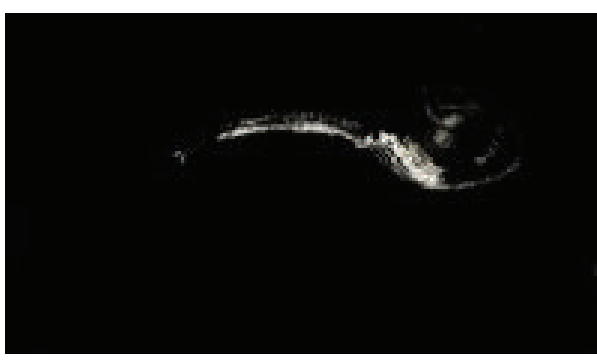

(a)

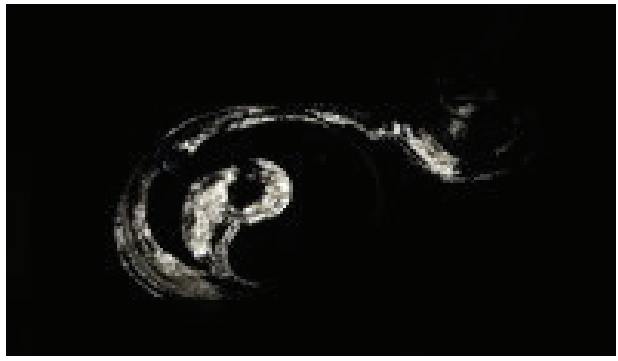

(c)

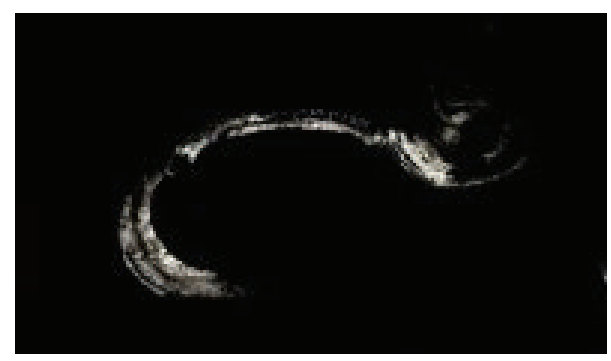

(b)

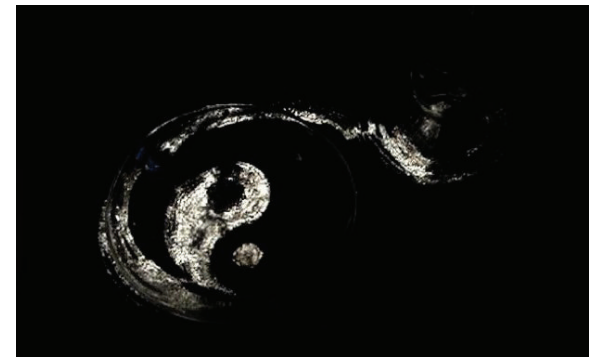

(d)

FIGURE 13: The thermochromic effects of the "tai chi" pattern with backlighting (5 V, 30 sec each, group 1(a), group 2(b), group 3(c), and group $4(d)$ in sequence).

namely, $5 \mathrm{~V}, 6 \mathrm{~V}, 7 \mathrm{~V}, 8 \mathrm{~V}$, and $9 \mathrm{~V}$, for the measurements of temperature rising rate and decoloration time. The results indicate a good linear relationship between temperatures and heating times (coefficient of determination $\left(R^{2}\right)=0.96$ for $5 \mathrm{~V}, 0.99$ for $6 \mathrm{~V}, 0.99$ for $7 \mathrm{~V}, 0.99$ for $8 \mathrm{~V}$, and 0.99 for $9 \mathrm{~V})$, and the temperature rising slope increases as voltage is increased. It also shows that the higher the voltage is applied, the quicker the thermochromic pattern vanishes away.

Based on the results of this research, a technique was developed that the manipulation of the pattern shape and color change rate on a thermochromic textile can be employed by embroidering the stainless steel conductive yarns into a specific pattern and altering the applied voltages. The patterns of Chinese calligraphy and "tai chi" were designed and the thermochromic effects were tested in a backlighting environment. The images of the Chinese calligraphy and "tai chi" pattern reveal a stone rubbing style and a "splash-ink" appearance which fits comfortably into the area of Chinese calligraphy and traditional Chinese painting illustrations. This result also demonstrates a range of new design research directions for thermochromic home textiles in the applications of interior decoration, furniture, and architecture.

\section{References}

[1] H. R. Mattila, Intelligent Textiles and Clothing, CRC Press, 2006.

[2] P. Bamfield, Chromic Phenomena, RSC Publishing, Cambridge, UK, 2001.

[3] X. Tao, Smart Fibres, Fabrics and Clothing, Woodhead, Cambridge, UK, 2001.

[4] L. Berglin, M. Ellwanger, L. Hallnäs, L. Worbin, and M. Zetterblom, "Smart textiles-what for and why?" The Nordic Textile Journal, pp. 47-49, 2005.

[5] L. Worbin, "Textile disobedience when textile patterns start to interact," The Nordic Textile Journal, pp. 51-69, 2005.

[6] S. Robertson, S. Taylor, R. Christie, J. Fletcher, and L. Rossini, "Designing with a responsive colour palette: the development of colour and pattern changing products," Advances in Science and Technology, vol. 60, pp. 26-31, 2008.

[7] Z. Berzina, "Charting and mapping the skin-research using analogies of human skin tissue in relation to my textile practice," Text for the Study of Textile, Art, Design and History, vol. 33, pp. $5-12,2005$.

[8] S. Seymour, Fashionable Technology, Springer, Wien, Austria, 2008.

[9] J. Berzowska, "Electronic textiles: wearable computers, reactive fashion, and soft computation," Textile, vol. 3, no. 1, pp. 58-75, 2005.

\section{Conflict of Interests}

The authors declare that there is no conflict of interests regarding the publication of this paper. 


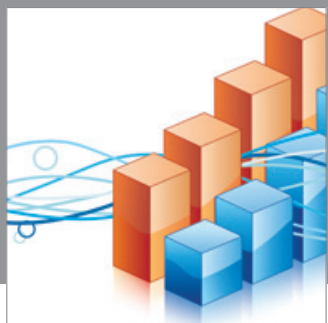

Advances in

Operations Research

mansans

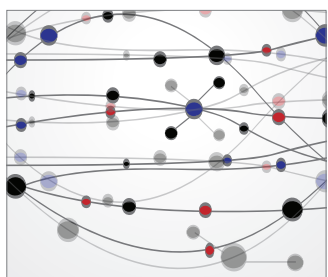

The Scientific World Journal
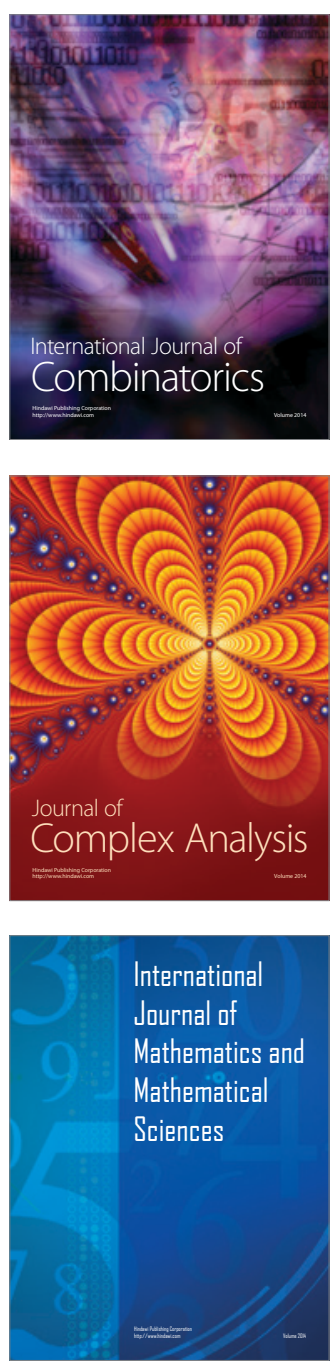
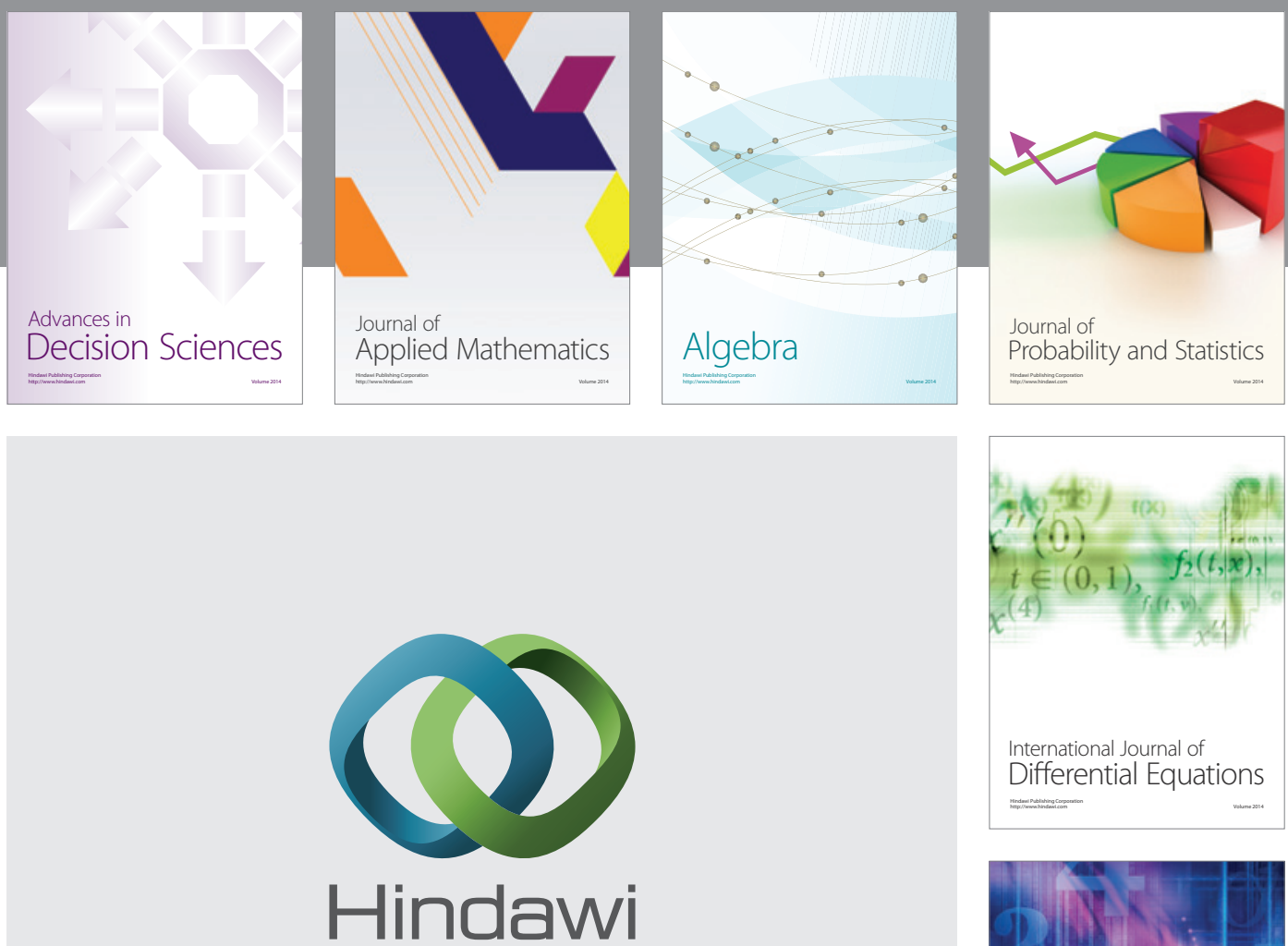

Submit your manuscripts at http://www.hindawi.com
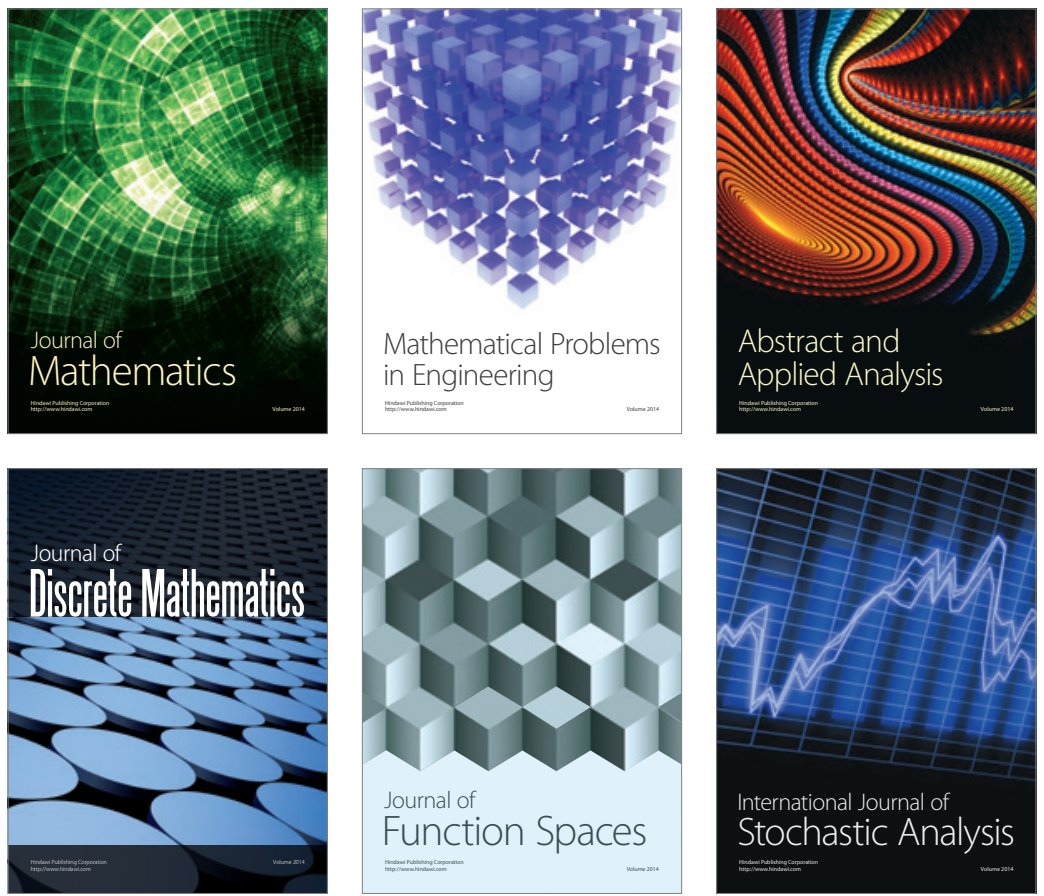

Journal of

Function Spaces

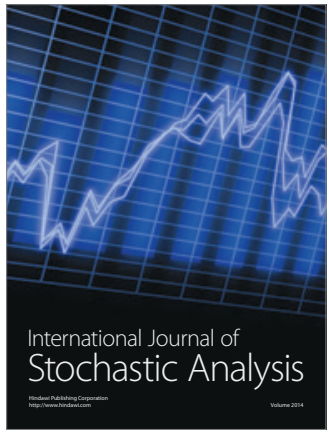

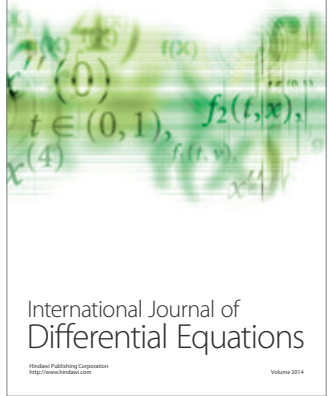
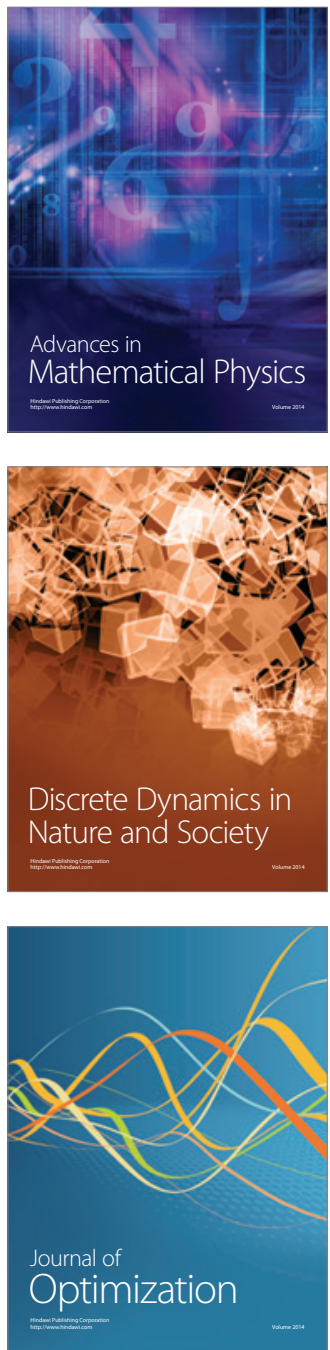